\title{
Publicidade e representações sociais no contexto da midiatização
}

\section{Raquel Ditz Ribeiro}

\section{Resumo:}

Este ensaio analisa como se dão as identificações na publicidade dentro do cenário da midiatização. Para tanto, propomos que é através das representações sociais presentes nas campanhas que a publicidade pode organizar sentidos que vão orientar estas identificações. Dessa forma, buscamos mostrar como a publicidade se relaciona com a criação dessa nova ambiência social que é a sociedade midiatizada. Para refletir sobre o assunto, o texto foi estruturado em três partes: na primeira abordamos o conceito de midiatização; na segunda descrevemos o funcionamento das representações sociais. E, enfim, na terceira, analisamos a publicidade como um campo de identificações no contexto da midiatização.

\section{Palavras Chave:}

midiatização, representações sociais, publicidade

\begin{abstract}
:
This essay analysis how the identifications work in advertisement in the mediatization scene. For such, we propose that through social representations in campaigns the advertisement can organize senses which will orient these identifications. In this way, we try to show how advertisement relates to the creation of this new social environment which is mediated society. To think about the subject, the text was structured in three parts: at the first part we approached the mediatization concept; at the second, we described how social representations work. At last, at the third part, we analyzed the advertisement as an identification field in mediatization context.
\end{abstract}

\section{Keywords:}

mediatization, social representations, advertisement

A proposta deste trabalho é discutir a publicidade como um campo de identificações no contexto da midiatização. Acreditamos que é através das representações sociais presentes nas campanhas que a publicidade pode organizar sentidos que vão orientar estas identificações. Dessa forma, buscamos mostrar como a publicidade se relaciona com a criação dessa nova ambiência social que é a sociedade midiatizada.

Com o objetivo de refletir sobre o tema, o texto foi estruturado em três partes. Na primeira, conceituamos midiatização e a relacionamos à publicidade. Na segunda parte, buscamos o conceito de representações sociais e tentamos desvelar algumas de suas imbricações coma a comunicação. Enfim, na terceira, analisamos a publicidade como um sistema simbólico que veicula representações e assim, produz identificações no contexto da midiatização.

\section{Midiatização}

A sociedade contemporânea encontra-se regida por uma certa virtualização das relações humanas. Isto está presente na articulação das tecnologias da comunicação com o funcionamento das instituições e da vida 
individual. Para Muniz Sodré, a midiatização

é uma ordem de mediações socialmente realizadas no sentido da comunicação entendida como processo informacional, a reboque de organizações empresarias e com ênfase num tipo particular de interação - a que poderíamos chamar de "tecnointeração" -, caracterizada por uma espécie de prótese tecnológica e mercadológica da realidade sensível, denominada «médium» (SODRÉ, 2002: 21-22).

A midiatização pode ser tomada como um dispositivo cultural que emerge em um contexto no qual o processo de comunicação é técnica e mercadologicamente redefinido pela informação, ou seja, por um produto que está a serviço do capital.

Sodré coloca que o conceito de midiatização não engloba o campo social em sua totalidade, e sim, "o da articulação hibridizante das múltiplas «instituições» (formas relativamente estáveis de relações sociais comprometidas com finalidades humanas globais), com as várias organizações de «mídia»" (SODRÉ, 2002: 24). Para ele, a midiatização é caracterizada por uma tendência a telerrealização ou virtualização das relações humanas que se encontra presente na articulação do múltiplo funcionamento institucional e de determinadas pautas individuais de conduta com as tecnologias da comunicação.

O autor faz ainda uma interessante colocação quando fala da existência de um quarto «bios», o «bios» midiático, a partir da classificação feita por Aristóteles em «Ética a Nicômaco» que distingue três gêneros de existência (bios) na Polis: o «bios theoretikos» (vida contemplativa), o «bios politikos» (vida política) e o «bios apolaustikos» (vida prazerosa, vida do corpo). Sendo assim, a midiatização é "um quarto âmbito existencial, onde predomina (muito pouco aristotelicamente) a esfera dos negócios, com uma qualificação cultural própria (a "tecnocultura")" (SODRÉ, 2002: 25).

Este novo bios implica em uma nova qualificação da vida que, para Sodré (2002), é capaz de criar uma eticidade estetizante e vicária onde através das tecnologias de comunicação a mídia se manifesta como poder simultâneo, instantâneo e global. A tecnocultura, que é constituída por mercado e meios de comunicação (o quarto bios) nos coloca frente a

uma transformação das formas tradicionais de sociabilização, além de uma nova tecnologia perceptiva e mental. Implica, portanto, um novo tipo de relacionamento do indivíduo com referências concretas ou com o que se tem convencionado designar como verdade, ou seja, uma outra condição antropológica (SODRÉ, 2002: 27).

Antônio Fausto Neto (2005) propõe que a nova vida tecno social gerada pela midiatização institui um novo tipo de real que está associado diretamente a novos mecanismos de produção de sentido. "Estes mecanismos produzem e fazem funcionar uma nova forma de sociedade, cujas finalidades são producionais, porém diretamente vinculadas às lógicas dos fluxos e das operações" (FAUSTO NETO, 2005: 03).

O pensamento de Jesús Martín-Barbero vai na mesma direção quando afirma que o que a revolução tecnológica introduz em nossas sociedades é um novo modo de relação entre os processos simbólicos e "as formas de produção e distribuição dos bens e serviços: um novo modo de produzir, confusamente associado a um novo modo de comunicar, transforma o conhecimento numa força produtiva direta" (BARBERO, 2006: $54)$.

É importante, neste contexto da midiatização, falarmos sobre a cultura da mídia. Para tanto, trazemos o pensamento de um estudioso no assunto, o autor Douglas Kellner (2006) para quem a cultura da mídia não aborda apenas grandes momentos da experiência contemporânea, mas também oferece material para fantasia 
e sonho (podemos incluir aqui a publicidade). Segundo o autor,

[...] na sociedade atual, o entretenimento e o espetáculo entraram nos domínios da economia, da política e do cotidiano, de novas e importantes maneiras. As formas contemporâneas de entretenimento, da televisão ao palco, estão incorporando a cultura do espetáculo aos negócios, transformando filmes, televisão, música, teatro e outros domínios da cultura, assim como produzindo formas espetaculares no ciberespaço, na multimídia e na realidade virtual (KELLNER, 2006: 128).

Diante desse contexto, buscamos analisar como se dão as representações sociais na publicidade neste cenário da midiatização. Nos dizeres de Sodré, "tudo tende a confluir para a imagem publicitária como valor coletivo, o que pode tornar a interpretação cênica da realidade mais importante do que qualquer modo tradicional de representação" (2002: 35).

O pensamento de Eneus Trindade e Valdemar Siqueira Filho se liga ao de Muniz Sodré quando os autores colocam que

a comunicação midiática publicitária, assim como outras formas de comunicação, tem uma responsabilidade social muito grande na formação do repertório cultural do indivíduo e que sua presença cotidiana e os seus respectivos processos de produção, bem como o consumo de seus produtos, geram uma nova ambiência social, ou seja, a sociedade midiatizada (TRINDADE \& FILHO, 2006: 05).

Assim, entendemos que o papel midiatizador dos meios de comunicação, com suas linguagens como a publicidade, são constitutivos das conjunturas socioculturais contemporâneas.

\section{Representações Sociais}

A Teoria das representações sociais, tal como foi desenvolvida por Serge Moscovici, está ligada à Psicologia Social. Segundo Morigi (2004), Moscovici atualizou o conceito sobre as representações coletivas elaborado em 1898 por Émile Durkheim. Dessa forma, o conceito tem origem nas Ciências Sociais, particularmente na Sociologia.

Na Psicologia Social, o conceito de representações sociais adquiriu uma importância muito grande. Este conceito alude às formas de familiarização com setores do mundo estranhos a nós, constituíndo-se de "uma série de proposições que possibilita que coisas ou pessoas sejam classificadas, que seus caracteres sejam descritos, seus sentimentos e ações sejam explicados e assim por diante" (MOSCOVICI, 2003: 209).

Para Denise Jodelet, Moscovici renovou a análise, insistindo sobre a especificidade dos fenômenos representativos contemporâneos. Com isso, foi possível uma primeira caracterização da representação social. A autora define a representação como "uma forma de conhecimento, socialmente elaborada e partilhada, com um objetivo prático, e que contribui para a construção de uma realidade comum a um conjunto social" (JODELET, 2001: 22). Ainda de acordo com Jodelet, as representações sociais estão sempre em ação na vida social, orientando e organizando as condutas e as comunicações sociais. Assim, elas devem ser estudadas "integrando a consideração das relações sociais que afetam as representações e a realidade material, social e ideativa sobre a qual elas têm de intervir" (JODELET, 2001: 26).

Para Moscovici (2001), o indivíduo sofre pressão das representações dominantes na sociedade e é nesse meio que pensa ou exprime seus sentimentos. Essas representações diferem de acordo com a sociedade em que nascem e são moldados. 
Em «The Work of Representation» (1997), Stuart Hall explica que existem três abordagens que determinam como funcionam as representações sociais. Para a primeira, a abordagem reflexiva, o significado está no objeto, pessoa, idéia ou evento do mundo real e a linguagem funciona como um espelho que reflete o verdadeiro significado, sendo que este já existe no mundo. Já a segunda, a abordagem intencional, diz que é o autor (a) que impõe ao mundo, através da linguagem seu significado único. Para Hall a abordagem intencional é problemática, já que "não podemos ser exclusivamente a única fonte de significados de uma linguagem, uma vez que isto significaria que poderíamos nos expressar em linguagens inteiramente particulares" (HALL, 1997: 25). A terceira abordagem é a construcionista ou construtivista, para a qual não devemos confundir o mundo material, onde as coisas e as pessoas existem; e, o mundo dos símbolos, através dos quais funcionam a representação, o significado e a língua. E é a terceira abordagem que interessa ao nosso trabalho, pois para ela

a representação envolve produzir significação forjando elos entre três diferentes ordens das coisas: o que podemos geralmente chamar de o mundo das coisas, pessoas, eventos e experiências; o mundo conceptual - os conceitos mentais que levamos em nossa mente; e os signos, arranjados nas línguas que "significam" ou comunicam estes efeitos (HALL, 1997: 61).

Sendo assim, os atores sociais vão utilizar um sistema cultural e lingüístico para construir os significados. A representação é então uma prática "que usa objetos e efeitos materiais, mas o significado depende não da qualidade material do signo, mas de sua função simbólica" (HALL, 1997: 25-26).

Jodelet afirma que "as representações sociais circulam nos discursos, são trazidas pelas palavras e veiculadas em mensagens e imagens midiáticas” (JODELET 2001, p. 17). Essa informação é complementada por Semin (2001), quando descreve que elas são entidades quase tangíveis, pois circundam, entrecruzam e cristalizam-se sem cessar por meio de uma fala, um gesto, um encontro, em nosso universo cotidiano.

Segundo Semin (2001), a maioria das relações sociais estabelecidas, dos objetos produzidos ou consumidos e das comunicações trocadas está impregnada de representações. Para Sandra Jovchelovitch e Pedrinho Guareschi (1995) a construção da significação simbólica é, simultaneamente, um ato de conhecimento e um ato afetivo. Tanto a cognição como os afetos que estão presentes nas representações sociais encontram sua base na realidade social.

As representações permitem a existência de símbolos, pedaços da realidade social mobilizados pela atividade criadora de sujeitos sociais para dar sentido e forma as circunstâncias em que eles se encontram. De acordo com Jovchelovitch (1995), enquanto fenômeno psicossocial, as representações sociais estão necessariamente radicadas no espaço público e nos processos através dos quais o ser humano desenvolve uma identidade, cria símbolos e se abre para a diversidade de um mundo de Outros.

Em um interessante trabalho, o pesquisador Murilo Cesar Soares (2007) revisa o conceito de representações e o coloca como uma referência primordial nos trabalhos analíticos sobre a cultura midiática. Para o autor, aparentemente, nas análises da comunicação midiática, "o objeto mais freqüente são as representações que aparecem sob a forma de encenação sobre pessoas, processos, estados, o que destaca a importância das formas analógicas, narrativas ou descritivas para a representação" (SOARES, 2007: 02).

Mas, mais importante ainda é o debate que o autor suscita ao contrastar representação e comunicação enquanto processos.

O conceito de representação, como anotamos, indica a construção de uma forma simbólica ou de um discurso sobre um evento do mundo empírico, implicando uma relação intrínseca entre o conhecimento e sistemas de signos usados para representá-lo. Já a comunicação está ligada à idéia de 
tornar comum, partilhar as representações e está muito associada aos processos de transmissão, envolvendo os meios. A comunicação corresponderia, assim, aos processos de socialização e intercâmbio das representações. Se nosso conhecimento do mundo implica a construção de uma representação sobre ele, comunicar é compartilhar essa representação através dos meios tecnológicos (SOARES, 2007: 06).

De acordo com esta proposição está o dizer de Valdir Morigi para quem ao relacionarmos as representações sociais com a comunicação temos um instrumento cultural que "age nas mediações do processo das identidades culturais, da sociabilidade, da memória social e das práticas políticas, sociais e culturais" (2004: 13). Ainda conforme o autor, as representações sociais disseminadas pelos meios de comunicação, passam a se constituírem realidades, as quais vêm a integrar o perfil da opinião pública em forma de discurso da atualidade, tornando-se parte do senso-comum.

Kathryn Woodward (2000) afirma que a representação inclui as práticas de significação e os sistemas simbólicos por meio dos quais os significados são produzidos, posicionando-nos como sujeito. É por meio dos significados produzidos pelas representações que damos sentido à nossa experiência e àquilo que somos.

\section{Publicidade e representações sociais no contexto da midiatização}

A publicidade pode ser vista como uma forma simbólica, transmitida culturalmente pelos meios de comunicação. Ao analisá-la como sistema simbólico utilizamos o enunciado por Elisa Piedras, para quem "ela se dedica a divulgar e promover a venda de outros sistemas e, através de suas campanhas e dos produtos que anuncia, opera a construção social das identidades, a partir das representações veiculadas" (PIEDRAS, 2004: 03).

Em outro ensaio, a autora também aborda a publicidade e seu imbricamento com a cultura.

[...] o processo de desenvolvimento de um esforço de comunicação em forma de publicidade consiste num sistema organizado e integrado, que se relaciona com a cultura de um determinado momento histórico em todas as suas instâncias. Pois a apropriação de elementos culturais viabiliza a identificação e o entendimento por parte do público com relação ao objetivo publicitário. E, posteriormente, esse esforço publicitário, aceito e percebido pelo público, vem transformar, contestar ou recompor, mesmo que sensivelmente, o contexto cultural da sua origem (PIEDRAS, 2005a: 04-05).

Assim, é importante que a publicidade não seja vista somente do ponto de vista mercadológico. Sua importância social, cultural e simbólica também deve ser considerada. Para Édison Gastaldo, além de ter sua finalidade comercial explícita, a publicidade vende ideologia, estereótipos e preconceitos e, ainda "forja-se um discurso que colabora na construção de uma versão hegemônica da realidade, legitimando uma dada configuração de forças no interior da sociedade" (GASTALDO, 2001: 07-08).

Segundo o autor, a publicidade dispõe de um certo espaço/tempo para otimizar os seus efeitos, assim "freqüentemente recorre à utilização de uma representação articulada com outras representações já existentes e culturalmente reconhecidas, otimizando a relação custo interpretativo/benefício cognitivo" (GASTALDO, 2002: 74).

Neste sentido, a publicidade pode ser vista como um lugar onde o sistema se reifica. Nilda Jacks confirma essa idéia quando diz que é vital para a publicidade "trabalhar com os valores e elementos constitutivos do sistema, sem os quais ela não realiza sua interação social” (JACKS, 2003: 124). É por isso que ela representa a sociedade em que está inserida, através de suas representações simbólicas. 
Para o autor Douglas Kellner a propaganda vende estilos de vida e identidades socialmente desejáveis e "os publicitários utilizam construtos simbólicos, com os quais o consumidor é convidado a identificar-se para tentar induzi-lo a usar o produto anunciado" (KELLNER, 2001: 324).

\section{Ainda de acordo com Kellner}

a propaganda "interpela" os indivíduos e convida-os a identificar-se com produtos, imagens e comportamentos. Apresenta uma imagem utópica de novidade, sedução, sucesso e prestígio mediante a compra de certos bens. Oferece magicamente uma autotransformação e uma nova identidade, associando as mudanças de comportamento, modo de vestir e aparência do consumidor com uma metamorfose em nova pessoa. Por conseguinte, os indivíduos aprendem a identificar-se com valores, modelos e comportamentos sociais através da propaganda, que é, portanto, um importante instrumento de socialização ao mesmo tempo que determina a demanda do consumidor (KELLNER, 2001: 322).

A publicidade ajuda a construir um complexo conjunto de representações que expressa identidades, diferenças, subjetividades, projetos, relações, comportamento, além de definir capitais sociais.

É neste contexto que os indivíduos vão encontrar os meios para a satisfação de seus desejos e necessidades, já que as mensagens publicitárias veiculam representações dos imaginários e memórias coletivas. Conforme Everardo Rocha, "a mensagem tem que falar a nossa língua, seus habitantes, no mais das vezes, se parecem fisicamente conosco ou pelo menos com alguns de nós" (ROCHA, 1995: 194). Além disso, deve possuir o nosso padrão de comportamento, estilo de vestuário, habitação, arte, tecnologia, lazer, usar os mesmos objetos, definir as mesmas práticas do sexo, da culinária, do mobiliário, da espacialização e da organização das cidades.

Ainda sobre as mensagens, Jacks comenta que é imprescindível que elas tenham como suporte "elementos lingüísticos e culturais que pertençam a um código comum à grande parte da população ou do segmento-alvo" (JACKS, 2003: 93). Desse modo, a publicidade produz um mundo idealizado, com base nas relações concretas de vida dos atores sociais, e atende as necessidades do público-alvo.

Segundo Rocha,

[...] o espectador de publicidade precisa acreditar no anúncio para que a vida ali projetada ofereça o sentido de gratuidade e abundância do consumo. O produto entra nas vidas projetadas pelo anúncio, funcionando como mágica. É improvável que o anúncio coloque algum problema, questão e impasse que ele mesmo não possa resolver. É uma marca da cultura representada dentro da propaganda que os bens de consumo supram as necessidades na forma como elas sã projetadas para serem supridas. Isto sem falar de "necessidades abstratas" como amor, carinho, afeto, alegria, e tantas mais que, de alguma forma, acabam também resolvidas ali dentro (ROCHA, 1995: 203).

Os anúncios humanizam e individualizam cada produto, tornando-o um objeto que convive e intervém no universo humano. Eles projetam uma maneira de ser, uma realidade, uma representação das necessidades humanas que inserem o produto na vida cotidiana. Dessa forma, a veiculação de representações sociais nos anúncios pode contribuir para produção/reprodução de identidades mediadas, neste caso, por padrões de consumo.

Ao analisarmos como a publicidade produz identificações no espaço midiatizado não podemos deixar de falar dos publicitários. Estes se apropriam de elementos culturais, codificando-os, atribuindo-lhes novos significados e relacionando-os àquilo que está sendo anunciado. E o público, no momento da recepção, 
reconstrói esses significados através de interpretações cultural e historicamente identificadas.

Os publicitários são representantes do cenário da midiatização, tanto em termos econômicos quanto ideológicos, já que além de vender produtos e serviços vendem também conceitos, valores e estilos de vida. Segundo Piedras,

os publicitários ocupam-se de reproduzir uma ideologia, em uma posição intermediária, em que poderes específicos são colocados em disputa pelos quatro protagonistas centrais do processo: os profissionais de criação, os profissionais de atendimento, os clientes e os consumidores, sendo os dois primeiros agentes a serviço da sistematização e racionalização de uma ideologia de consumo, que o terceiro grupo deseja colocar ao quarto (PIEDRAS, 2005b: 24-25).

Neste contexto, podemos inserir o pensamento de Everardo Rocha (1995), para quem a publicidade é uma espécie de "cola" do sistema e tudo que está na mídia é entretecido pelos anúncios. Ao falar de publicidade o autor diz que é através dela que tudo vem a se ligar com tudo e, "é ela que irrompe nas páginas dos jornais e revistas, nas vozes do rádio ou nas imagens das televisões de maneira inapelável, como que enfatizando o lugar de fato e de direito que dispõe por costurar todo o sistema" (ROCHA, 1995: 42).

No entanto, é importante não vermos a publicidade somente do seu ponto de vista mercadológico (como já foi dito). De acordo com esta proposição, estão os dizeres de Piedras.

O fato de a publicidade ter como principal função a divulgação de bens e serviços com o objetivo de gerar vendas e reproduzir o modo de produção capitalista, não exclui sua dimensão cultural, que constrói representações sociais e atualiza o imaginário contemporâneo, além de contribuir para criar ou reafirmar práticas (PIEDRAS, 2005b: 62).

Dessa forma, vemos que a publicidade pode ser constituída por formas sociais já institucionalizadas e, ao mesmo tempo, constituir novos valores e ações sociais. Assim, ela é muito mais que um processo comunicacional condicionado por uma estrutura social e histórica (no caso deste ensaio o contexto da midiatização). A publicidade é, na verdade, um sistema que articula sua produção com as práticas cotidianas do sujeito e, com essa estrutura mais ampla.

\section{Considerações finais}

No contexto da midiatização temos a mídia como uma das principais responsáveis pelos processos de interação social e também de construção de subjetividades. Este poder da mídia é exercido simbolicamente através de seus meios e mensagens, entre os quais destacamos a publicidade.

Acreditamos que é através das representações que a publicidade exerce o poder de sistema simbólico, isto é, produz um campo de identificações. As representações fazem parte de um ambiente social e cultural onde se dão pensamentos e ações dos seres humanos.

Dessa forma, podemos ver a publicidade agindo como um campo de identificações no espaço midiatizado, já que ela põe em relação identidades, grupos e representações coletivas. Assim, não podemos analisá-la somente no seu contexto mercadológico, mas também pelos valores e sentidos que transmite e organiza nesta nova ambiência social que é a midiatização. 


\section{Bibliografia:}

FAUSTO NETO, Antônio. Midiatização, prática social - prática de sentido. Trabalho apresentado no Encontro da Rede Prosul - Comunicação, Sociedade e Sentido, no seminário sobre Midiatização, UNISINOS, São Leopoldo, 19/12/2005 e 06/01/2006.

GASTALDO, Edison Luis. “Um tempo para jogar: o ser brasileiro na publicidade da Copa de 1998”. Revista Campos. n. 01. 2001. Disponível em: calvados.c3sl.ufpr.br/campos. Acesso em: 14/08/2005.

. Pátria, chuteiras e propaganda: o brasileiro na publicidade da Copa do Mundo. São Paulo:

Annablume; São Leopoldo: Ed. Unisinos, 2002.

GUARESCHI, Pedrinho A. \& JOVCHELOVITCH, Sandra. Textos em Representações Sociais. Petrópolis: Vozes, 1995.

HALL, Stuart. “The Work of Representation”. In: HALL, Stuart. (org.). Representation. Cultural Representations and Signifying Practices. Sage/Open University: London/Thousand Oaks/New Delhi, 1997.

JACKS, Nilda. Mídia Nativa: indústria cultural e cultura regional. Porto Alegre: Ed. Universidade/UFRGS, 1998.

JODELET, D. As Representações Sociais. Rio de Janeiro: EdUERJ, 2001.

JOVCHELOVITCH, Sandra. "Vivendo a vida com os outros: intersubjetividade, espaço público e Representações Sociais”. In: GUARESCHI, Pedrinho A. \& JOVCHELOVITCH, Sandra. (orgs.). Textos em Representações Sociais. Petrópolis: Vozes, 1995.

KELLNER, D. A cultura da mídia - estudos culturais: identidade e política entre o moderno e o pós-moderno. Bauru: EDUSC, 2001.

. "Cultura da mídia e triunfo do espetáculo". In: MORAES, Dênis de. (org.). Sociedade Midiatizada. Rio de Janeiro: Mauad, 2006.

MARTIN-BARBERO, Jesús. "Tecnicidades, Identidades, Alteridades: mudanças e opacidades da comunicação no novo século”. In: MORAES, Dênis de. (org.). Sociedade Midiatizada. Rio de Janeiro: Mauad, 2006.

MORIGI, Valdir José. “Teoria Social, Comunicação: Representações Sociais, Produção de Sentidos e Construção dos Imaginários Midiáticos”. Revista Eletrônica e-compos, n. 01. dezembro de 2004. Disponível em: www.compos.org.br/e-compos. Acesso em: 31/03/2005.

MOSCOVICI, Serge. "Das representações coletivas às representações sociais: elementos para uma história". In: JODELET, Denise. (org.). As Representações Sociais. Rio de Janeiro: EdUERJ, 2001.

. Representações sociais: investigações em Psicologia Social. Petrópolis: Vozes, 2003.

PIEDRAS, Elisa Reinhardt. Publicidade, representação e identidade: a cultura brasileira na estratégia das 
Havaianas. XXVII Congresso Brasileiro de Ciências da Comunicação (Intercom, 2004. Disponível em: www.adtevento.com.br/intercom/resumos/RO499-1.pdf. Acesso em: 03/04/2005.

. A transformação da publicidade em diferentes contextos sócio-históricos no Brasil: Análise de peças publicitárias como testemunhos culturais. Grupo de Trabalho História da Publicidade e Propaganda, Universidade Federal de Santa Catarina, 2005a. Disponível em:

www.jornalismo.ufsc.br/redealcar/cd3/pp/elisareinhardtpiedras.doc. Acesso em: 28/08/05.

. A articulação da publicidade com o mundo social: a constituição do fluxo publicitário nas práticas de produção e recepção. Dissertação de Mestrado. Programa de Pós-Graduação em Comunicação e Informação, UFRGS, Porto Alegre, 2005b.

SEMIN, G. "Protótipos e representações sociais". In: JODELET, Denise. (org.). As Representações Sociais. Rio de Janeiro: Eduerj, 2001.

SODRÉ, Muniz. Antropológica do espelho: uma teoria da comunicação linear e em rede. Petrópolis: Vozes, 2002.

ROCHA, Everardo. A Sociedade do Sonho: comunicação, cultura e consumo. Rio de Janeiro: Mauad, 1995.

SOARES, Murilo César. Representações da cultura mediática: para a crítica de um conceito primordial. Trabalho apresentado ao GT Cultura das Mídias. XVI Compós, UTP, Curitiba, 2007. Disponível em: www.compos.org.br/data/biblioteca_204.pdf. Acesso em: 28/06/2007.

TRINDADE, Eneus \& FILHO, Valdemar Siqueira. O capital simbólico da publicidade em contextos midiatizados: uma reflexão teórica. Anais do XI Simpósio de Ciências da Comunicação na Região Sudeste, Ribeirão Preto, SP, 22 a 24 de maio de 2006.

\section{Mini Currículo :}

Bacharel em Comunicação Social - Publicidade e Propaganda pela Universidade Federal de Santa Maria (UFSM) e mestranda do Programa de Pós-Graduação em Comunicação Midiática da UFSM. E-mail: raquelditz@yahoo.com.br. 